\title{
Veno-Venous Extra-Corporeal Membrane Oxygenation (ECMO) in a Child with Hemoptysis and Fontan Circulation
}

\section{Claudine Kumba1,2* ${ }^{(\mathbb{0}}$, Gauthier Loron ${ }^{3}$, Anais Mons ${ }^{3}$, Claude Marcus ${ }^{4}$, Francis Grossenbacher ${ }^{5}$, Nathalie Bednarek-Weirauch ${ }^{3}$, Vito Giovanni Ruggieri ${ }^{6}$, Emre Belli ${ }^{7}$, Jean-Marc Malinovsky ${ }^{1}$, Pierre Mauran 8}

\author{
${ }^{1}$ Department of Anesthesia and Critical Care, CHU Reims, Reims, France \\ ${ }^{2}$ Department of Pediatric Anesthesia and Critical Care, HU Necker Enfants Malades University Hospital, Assistance Publique \\ Hôpitaux de Paris, Paris, France \\ ${ }^{3}$ Department of Pediatric and Neonatal Intensive Care, CHU Reims, Reims, France \\ ${ }^{4}$ Department of Radiology, CHU Reims, Reims, France \\ ${ }^{5}$ Department of Intensive Care and Emergency Medicine, CHU Reims, Reims, France \\ ${ }^{6}$ Department of Thoracic and Cardiovascular Surgery, CHU Reims, Reims, France \\ ${ }^{7}$ Department of Pediatric Cardiac Surgery, Marie Lannelongue Hospital, Le Plessis Robinson, France \\ ${ }^{8}$ Department of Pediatric Cardiology and Congenital Heart Diseases, American Memorial Hospital, CHU Reims, Reims, France \\ Email: *claudine.kumba@gmail.com, ${ }^{\star}$ claudine.kumba@aphp.fr
}

How to cite this paper: Kumba, C., Loron, G., Mons, A., Marcus, C., Grossenbacher, F., Bednarek-Weirauch, N., Ruggieri, V.G., Belli, E., Malinovsky, J.-M. and Mauran, P. (2020) Veno-Venous Extra-Corporeal Membrane Oxygenation (ECMO) in a Child with Hemoptysis and Fontan Circulation. Open Journal of Pediatrics, 10, 280-287. https://doi.org/10.4236/ojped.2020.102029

Received: April 27, 2020

Accepted: May 17, 2020

Published: May 20, 2020

Copyright (c) 2020 by author(s) and Scientific Research Publishing Inc. This work is licensed under the Creative Commons Attribution International License (CC BY 4.0).

http://creativecommons.org/licenses/by/4.0/ (c) (i) Open Access

\begin{abstract}
Background: Extracorporeal membrane oxygenation is a rescue life support technique used in life threatening conditions of refractory respiratory and/or cardiac distress. Indication for extracorporeal life support in children depends on age and varies from pulmonary to cardiac pathologies. In some cases, it may be used as a bridge to a therapeutic procedure. We described here the management of respiratory failure due to hemoptysis in a child with a Fontan circulation and veno-venous extracorporeal membrane oxygenation which served as a bridge to angio-embolization. Hemoptysis can be a life threatening condition which can lead to hypovolemic shock and impaired alveolar gas exchange. The latter can result in respiratory failure and consequent asphyxia. When hemoptysis occurs in a patient with a univentricular heart and a Fontan circulation, management of this clinical situation can be challenging due to the particular physiology of the latter. Total cavopulmonary connection is a palliative surgical repair which constitutes Fontan circulation as a definitive treatment in patients with a univentricular heart. Methods: Case report description of a 16 year-old boy with a univentricular heart and a Fontan circulation who presented hemoptysis managed with a veno-venous extracorporeal membrane oxygenation (ECMO) as a bridge to an-
\end{abstract}


gio-embolization. Results: Hemoptysis due to diffuse intra-alveolar hemorrhage from collateral circulation was successfully treated in this young patient with pulmonary vascular embolization. This allowed to wean the patient from extra-corporeal membrane oxygenation. Conclusion: Veno-venous ECMO can be life-saving as a bridge to angio-embolization for severe hemoptysis in patients with Fontan circulation. The reported case allows to underline that our multidisciplinary approach in this complex pediatric patient surely participated to improve outcome.

\section{Keywords}

Extracorporeal Membrane Oxygenation, Fontan Circulation, Univentricular Heart, Tricuspid Atresia, Children, One Lung Ventilation, Mobile ECMO Team, Pediatric Anesthesia and Critical Care, Angio-Embolization, Interventional Radiology, Pediatric Cardiology, Pediatric Cardiac Surgery, Trans-Thoracic Echocardiography Aortic Velocity Time Integral, Fluid Responsiveness, Goal Directed Fluid and Hemodynamic Therapy

\section{Introduction}

Extracorporeal membrane oxygenation (ECMO) in the neonatal and pediatric population has been developed more than 45 years ago [1]. This extracorporeal life support (ECLS) technique has been used in life threatening situations of respiratory and/or cardiac failure as a rescue therapy. Several indications for ECMO implantation have been reported and depend on patient age [1]. These included asthma, bronchiolitis, pneumonia, non-pulmonary infection, drowning, inhalation, foreign body, trauma, congenital heart disease, congenital diaphragmatic hernia, meconium aspiration syndrome, persistent pulmonary hypertension of the newborn, respiratory distress syndrome and sepsis [1].

Other indications for ECLS are endotracheal tumor resection, tracheal resection, complex tracheoesophageal fistulae, dislodged stents, foreign body removal, control of hemoptysis, debridement of papillomatosis, relief of external compression, difficult or impossible one lung ventilation, mediastinal masses and lung transplantation [2].

Survival rate at discharge from hospital when ECMO is used for cardiac disease in neonates and older children is $42 \%$ and $41 \%$ respectively [3]. Survival at hospital discharge for respiratory disease, when ECMO is used in neonates and older children, is $74 \%$ and $58 \%$, respectively [3]. Veno-venous ECMO is used for primary refractory respiratory failure. ECMO system is constituted by a centrifugal pump, a membrane oxygenator and an integrated circuit of tubing connected to the patient by two canulas, drainage and infusion.

In the veno-venous ECMO (VVECMO), the drainage canula is inserted through the right femoral vein into the inferior vena cava in order to drain patient blood for oxygenation and carbon dioxide $\left(\mathrm{CO}_{2}\right)$ removal by the membrane 
oxygenator; the infusion canula is inserted through the right jugular vein and to the right atrium in order to reinject oxygenated blood into the patient and to the left heart and systemic circulation [2].

Veno-arterial ECMO (VAECMO) is used for hemodynamic and circulatory support with or without respiratory dysfunction. In this setting, the drainage canula is usually inserted through the femoral vein in order to bring patient blood to the membrane oxygenator; the arterial canula is usually inserted through the common femoral artery to reinject oxygenated blood coming from membrane oxygenator into the aorta. With this ECLS, the lungs and the right ventricle are unloaded [2].

VVECMO and VAECMO have been used as a bridge to palliative or corrective surgery in children with congenital heart disease and demonstrated a survival rate at discharge from hospital of more than $60 \%$ [4].

VVECMO has been used in children with diffuse intra-alveolar hemorrhage as a bridge to treatment with successful results [5] [6].

We report here the management of hemoptysis with VVECMO in a 16 year-old boy with a univentricular heart and a Fontan circulation. In this particular setting, both vena cava, disconnected from the heart, drain systemic venous blood directly into the pulmonary arteries.

\section{Case Report}

A 16 year-old boy was admitted for hemoptysis in the pediatric intensive care unit (PICU) on 24 January 2019 in Reims. History was characterized by a type IC tricuspid atresia. He had a partial cavo-pulmonary anastomosis with section-ligation of the main pulmonary artery at the age of 3 months and Fontan completion surgery with a fenestrated $18 \mathrm{~mm}$ extracardiac conduit at the age 18 months. Before the present one, he had already experienced 4 episodes of hemoptysis 5, 2.5 and 1.5 years earlier for which he had underwent 3 successful angio-embolizations. The fourth episode of hemoptysis which had occurred 1.5 years before the present one spontaneously resolved after antivitamin $\mathrm{K}$ therapy withdrawal, previously administered because of a right atrial thrombus. He had no history of allergy and was taking $75 \mathrm{mg}$ of aspirin as sole medication.

At admission to the PICU the patient was hemodynamically stable with normal hemoglobin levels and coagulation laboratory tests. A thoracic computed tomographic scan (CT-scan) showed intra-alveolar hemorrhage of the lingula, inferior and superior lobes and three right intra-atrial partially calcified thrombi.

Vascular embolization was decided as treatment to stop bleeding. Just before going to the interventional radiologic ward, the patient suddenly presented massive hemoptysis requiring selective intubation of the left bronchus with a left Carlens tube to exclude the left bleeding lung; this was realized under general anesthesia with etomidate and after topic anesthesia of the glottis with lidocaine. The patient was then transferred to the interventional ward for angio-embolization. He was spontaneously breathing with mild pressure support under sedation with 
propofol and ketamine which was switched to volume control ventilation because of fatigue.

At this time, angio-embolization did not succeed to control the bleeding. The patient developed severe respiratory acidosis with a $\mathrm{pH}$ of 6.9 and $\mathrm{PaCO}_{2}$ of 145 $\mathrm{mmHg}$, despite mechanical ventilation with volume control and adequate sedation. Taking into account the cardiac surgical history, the complex congenital heart disease, the risk of severe hypercarbia and the ongoing hemoptysis, we decided to urgently assist patient with ECMO. A veno-venous ECMO implantation was realized by the cardiac surgeon with canulation of the right femoral vein for blood drainage and the right internal jugular vein for blood reinjection. ECMO settings were chosen under echocardiographic monitoring of ventricular filling and cardiac output. The ECMO output was set between 1 and 1.5 liters/min which allowed the central mixed venous oxygen saturation $\left(\mathrm{SVO}_{2}\right)$ measured on the ECMO to raise from undetectable values to $70 \%-75 \%$. Cardiac output and fluid hemodynamic status responsiveness were assessed echocardiographically using the Integral Time Velocity (ITV) at the aortic valve.

On ECMO, hemodynamic and respiratory states of the patient improved with normalization of the $\mathrm{pH}$ and $\mathrm{PaCO}_{2}$ to 7.38 and $37.3 \mathrm{mmHg}$, respectively. In the meantime, the patient received fluid therapy with $1500 \mathrm{ml}$ of crystalloids and was transfused with four units of packed red blood cells and three fresh frozen plasma units and received three grams of calcium chlorid. His hemodynamic state and bleeding remained stable at this time with normal hemoglobin levels and vital parameters.

After stabilization of the hemodynamic and respiratory states, the patient was transferred to a high-volume reference center of our French network for management of patients with congenital heart diseases.

Two consecutive angio-embolizations sessions were necessary to stop bleeding. The patient was weaned from ECMO and mechanical ventilation 14 days after admission. He presented during the hospitalization, 22 days later, 2 episodes of seizures for which he received $1000 \mathrm{mg}$ twice daily of levetiracetam and $1 \mathrm{mg}$ per day of clonazepam.

Cerebral magnetic resonance imaging (MRI) and computed tomographic scan (CT-scan) were not conclusive. The electroencephalogram was normal. He presented during the hospitalization toe ischemic lesions with favorable outcome. Finally, the patient had a favorable outcome and was discharged home with 100 $\mathrm{mg}$ per day of aspirin and $1000 \mathrm{mg}$ twice daily of levetiracetam.

\section{Discussion}

Although major aorto-pulmonary collateral arteries (MAPCAs) are usually found in pulmonary atresia with ventricular septal defect, they are not uncommon in univentricular hearts [7] and can be responsible for severe hemoptysis [8] as it was the case in our patient.

Angio-embolization was the first therapeutic choice in this patient because 
less invasive than surgery. In this patient, surgery could have been more complicated due to the cardiac surgical history and increased operative risk [8].

One lung ventilation in this setting can be an issue because of the specific Fontan circulation physiology with a single ventricle. In the Fontan circulation, deoxygenated blood flows from the superior vena cava and the inferior vena cava towards the pulmonary arteries without being pumped by the heart. Only a small increase in pulmonary vascular resistance can compromise blood flow through the lungs and consequently blood oxygenation.

Spontaneous ventilation is highly preferable in Fontan patients in order to minimize pulmonary vascular resistance and pressure, compared to intrathoracic pressure increase induced by mechanical ventilation. The issue with spontaneous ventilation is fatigue if the procedure is too long and that can compromise optimal ventilation.

In the present case, the left lung was not ventilated because of massive hemorrhage for which a selective bronchial intubation was necessary to exclude the bleeding lung but also to protect the non-bleeding lung.

Hypercarbia can occur due to the non-ventilated but perfused lung. In the Fontan circulation mild hypercarbia of 40 - $45 \mathrm{mmHg}$ may be beneficial because it increases cerebral blood flow and thus can increase flow to the pulmonary circulation [9]. However, severe hypercarbia can increase pulmonary vascular resistance and thus compromise blood oxygenation. If hypoxemia occurs, it may cause hypoxic pulmonary vasoconstriction which increases pulmonary resistance and compromises Fontan circulation [9].

Veno-venous ECMO was performed to reduce hypercarbia, respiratory acidosis and prevent hypoxemia due to intra-alveolar hemorrhage which could have had serious adverse outcome in this patient's hemodynamic status. The extracorporeal life support in this setting was used as a bridge to treatment of the pulmonary hemorrhage with angio-embolization. Veno-venous ECMO has been described as a bridge treatment in diffuse intra-alveolar hemorrhage and has been shown to be efficient in this setting [7] [10]. This technique has also been used in other primary respiratory failures with good results in children [11]. Veno-arterial ECMO has been used for ECLS in Fontan circulation with cardiac failure described as "failing Fontan" [12]. This condition can have different etiologies such as arrhythmias, thrombosis of cavo-pulmonary anastomosis, increase in pulmonary vascular resistance and diastolic and systolic univentricular dysfunction. The efficiency of ECMO in the failing Fontan depends on venous drainage [12]. Survival after ECMO in a failing Fontan varies from 35\% to 50\% depending on the studies [12]. The patient described in the present case report did not have a failing Fontan circulation as demonstrated by our echocardiographic findings prior to ECMO instauration. Diastolic and systolic functions were normal. There was no arrythmia and the cavo-pulmonary anastomoses were widely permeable.

Indication for ECMO was primary respiratory failure secondary to hemopty- 
sis. A veno-venous ECMO was used in the present patient who was suffering from primary respiratory distress because of severe hemoptysis. Survival rates are higher in patients with a single ventricle on VVECMO for primary respiratory failure than in patients on VAECMO for cardiac dysfunction (48\% vs $32 \%$ 43\%) [13].

In Fontan patients, a high VVECMO output is necessary to maintain a venous pressure high enough to ensure pulmonary circulation and single ventricle preload. We believe that echocardiographic monitoring of pulmonary blood flow and ventricular filling is mandatory for proper VVECMO settings in these patients. It has been previously reported that if veno-venous ECMO is not effective it can be converted to a veno-arterial ECMO [12].

In the present case, VVECMO was efficient to bridge the patient to angioembolization. Whereas veno-arterial ECMO is used in cases of cardiac failure with or without respiratory insufficiency, veno-venous ECMO is generally performed in primary respiratory failure and in some congenital heart diseases [2] [3] [4]. In the present case, respiratory acidosis was improved under VVECMO. ECMO associated with $\mathrm{CO}_{2}$ removal reduced length of mechanical ventilation in patients with acute respiratory distress syndrome and if low tidal volume ventilation is used [14].

It has been evidenced that survival is improved when patients with ECMO are managed in high volume centers [15] [16] and it was the main reason to transfer the patient. Transporting a patient under ECMO requires a specialized mobile ECMO team. In several countries these teams are under development or well established yet [15] [16]. In France, transport of a patient under ECMO is yet mostly managed with the help of Emergency Medical Service and since 2006 in Reims [17].

Secondary adverse effects have been reported under ECMO, such as neurologic complications, risk of bleeding, air emboli, limb ischemia, infection, thrombosis, renal failure, hemolysis, heparin induced thrombocytopenia [2]. Incidence of bleeding is $70.2 \%$ and $37.5 \%$ for thrombosis [18] in children under ECMO.

In the present case, the patient had seizures and peripheral ischemic lesions with favorable outcome. Although MRI and CT-scan cerebral imaging did not show evidence of ischemic lesions, emboli remain highly suspected. ECMO, repeated catheterization sessions and intracardiac thrombus were potential causes of emboli which could have explained the clinical presentation.

\section{Conclusions}

We reported a complex and critical congenital case of a young patient successfully treated with VVECMO during severe hemoptysis in a context of a univentricular heart with Fontan circulation. In this particular and critical situation, a multidisciplinary therapeutic approach of this patient was mandatory to improve his outcome. 
The innovating aspect of this case report was the use of a VVECMO as a bridge to angioembolization in a patient with a Fontan circulation presenting hemoptysis and the use of transthoracic echocardiographic aortic blood flow peak velocity time integral variation to monitor fluid responsiveness for fluid and hemodynamic therapy in a complex congenital heart disease.

\section{Funding}

There was no funding

\section{Ethic Approval}

The parents give informed consent and permission to publish this case report.

\section{Conflicts of Interest}

The authors declare no conflicts of interest regarding the publication of this paper.

\section{References}

[1] Bembea, M., Hoskote, A. and Guerguerian, A.M. (2018) Pediatric ECMO Research: The Case for Collaboration. Frontiers in Pediatrics, 6, 240.

https://doi.org/10.3389/fped.2018.00240

[2] McRae, K. and De Perrot, M. (2018) Principles and Indications of Extracorporeal Life Support in General Thoracic Surgery. Journal of Thoracic Disease, 10, S931-S946. https://doi.org/10.21037/jtd.2018.03.116

[3] Harvey, C. (2018) Cannulation for Neonatal and Pediatric Extracorporeal Membrane Oxygenation for Cardiac Support. Frontiers in Pediatrics, 6, 17. https://doi.org/10.3389/fped.2018.00017

[4] Bautista-Hernandez, V., Thiagaran, R.R., Fynn-Thompson, F., et al. (2009) Preoperative Extracorporeal Membrane Oxygenation as a Bridge to Cardiac Surgery in Children with Congenital Heart Disease. The Annals of Thoracic Surgery, 88, 1306-1311. https://doi.org/10.1016/j.athoracsur.2009.06.074

[5] Dalabih, A., Pietsch, J., Jabs, K., et al. (2012) Extracorporeal Membrane Oxygenation as a Platform for Recovery: A Case Report of a Child with Pulmonary Hemorrhage, Refractory Hypoxemic Respiratory Failure, and New Onset Goodpasture Syndrome. The Journal of Extra-Corporeal Technology, 44, 75-77.

[6] Kimura, D., Shah, S., Briceno-Medina, M., et al. (2015) Management of Massive Diffuse Alveolar Hemorrhage in a Child with Systemic Lupus Erythematosus. Journal of Intensive Care, 3, 10. https://doi.org/10.1186/s40560-015-0076-5

[7] Patrick, W.L., Mainwaring, R.D., Reinhartz, O., et al. (2017) Major Aortopulmonary Collateral Arteries with Anatomy Other Than Pulmonary Atresia/Ventricular Septal Defect. The Annals of Thoracic Surgery, 104, 907-916. https://doi.org/10.1016/j.athoracsur.2017.02.029

[8] Bédard, E., Lopez, S., Perron, J., et al. (2008) Life-Threatening Hemoptysis Following the Fontan Procedure. Canadian Journal of Cardiology, 24, 145-147. https://doi.org/10.1016/S0828-282X(08)70572-5

[9] Andropoulos, D., Stayer, S., Mossad, E.B. and Miller-Hance, W.C. (2015) Anesthesia for Congenital Heart Disease. Houston Texas USA. 3rd Edition, Wiley Blackwell, 
New York, 590-597. https://doi.org/10.1002/9781118768341

[10] Lee, J.H. and Kim, S.H. (2013) Successful Management of Warfarin-Exacerbated Diffuse Alveolar Hemorrhage Using an Extracorporeal Membrane Oxygenation. Multidisciplinary Respiratory Medicine, 8, 16.

https://doi.org/10.1186/2049-6958-8-16

[11] Turek, J.W., Andersen, N.D., Lawson, S.D., et al. (2013) Outcomes Before and After Implementation of a Pediatric Rapid-Response Extracorporeal Membrane Oxygenation Program. The Annals of Thoracic Surgery, 95, 2140-2147. https://doi.org/10.1016/j.athoracsur.2013.01.050

[12] Bacon, M.K., Gray, S.B., Schwartz, S.M., et al. (2018) Extracorporeal Membrane Oxygenation (ECMO) Support in Special Patient Populations-The Bidirectional Glenn and Fontan Circulations. Frontiers in Pediatrics, 6, 299.

https://doi.org/10.3389/fped.2018.00299

[13] Nair, A.B., Oishi, P., et al. (2016) Venovenous Extracorporeal Life Support in Single-Ventricle Patients with Acute Respiratory Distress Syndrome. Frontiers in Pediatrics, 4, 66. https://doi.org/10.3389/fped.2016.00066

[14] Bein, T., Weber-Carstens, S., Goldmann, A., et al. (2013) Lower Tidal Volume Strategy $\left(3 \mathrm{ml} / \mathrm{kg}\right.$ ) Combined with Extracorporeal $\mathrm{CO}_{2}$ Removal versus 'Conventional' Protective Ventilation $(6 \mathrm{ml} / \mathrm{kg}$ ) in Severe ARDS. The Prospective Randomized Xtravent-Study. Intensive Care Medicine, 39, 847-856. https://doi.org/10.1007/s00134-012-2787-6

[15] Broman, L.M. (2017) Inter-Hospital Transports on Extracorporeal Membrane Oxygenation in Different Health-Care Systems. Journal of Thoracic Disease, 9, 3425-3429. https://doi.org/10.21037/jtd.2017.07.93

[16] Broman, M. and Frenckner, B. (2016) Transportation of Critically Ill Patients on Extracorporeal Membrane Oxygenation. Frontiers in Pediatrics, 4, 63. https://doi.org/10.3389/fped.2016.00063

[17] Grinda, J.M., Bricourt, M.O., Salvi, S., Carlier, M., Grossenbacher, F., Brasselet, C. and Fabiani, J.N. (2006) Unsual Cardiogenic Shock Due to Pheochromocytoma: Recovery after Bridge-to-Bridge (Extracorporeal Life Support and DeBackey Ventricular Assist Device) and Right Surrenalectomy. The Journal of Thoracic and Cardiovascular Surgery, 131, 913-914. https://doi.org/10.1016/j.jtcvs.2005.12.021

[18] Dalton, H.J., Reeder, R., Garcia-Filion, P., et al. (2017) Factors Associated with Bleeding and Thrombosis in Children Receiving Extracorporeal Membrane Oxygenation. American Journal of Respiratory and Critical Care Medicine, 196, 762-771. https://doi.org/10.1164/rccm.201609-1945OC 